\title{
(2) OPEN ACCESS \\ Effectiveness of a medication adherence management intervention in a community pharmacy setting: a cluster randomised controlled trial
}

\author{
Andrea Torres-Robles, ${ }^{1}$ Shalom I Benrimoj, ${ }^{2}$ Miguel Angel Gastelurrutia, ${ }^{2}$ \\ Fernando Martinez-Martinez, ${ }^{2}$ Tamara Peiro, ${ }^{3}$ Beatriz Perez-Escamilla, ${ }^{2}$ \\ Kris Rogers, ${ }^{1}$ Isabel Valverde-Merino, ${ }^{2}$ Raquel Varas-Doval, ${ }^{3}$ \\ Victoria Garcia-Cardenas (1) ${ }^{1}$
}

- Additional material is published online only. To view, please visit the journal online (http://dx.doi.org/10.1136/ bmjqs-2020-011671).

${ }^{1}$ Graduate School of Health, University of Technology Sydney, Sydney, New South Wales, Australia

${ }^{2}$ Pharmaceutical Care Research Group, Universidad de Granada Facultad de Farmacia, Granada, Andalucía, Spain

${ }^{3}$ General Pharmaceutical Council of Spain, Madrid, Spain

\section{Correspondence to} Dr Victoria Garcia-Cardenas, Graduate School of Health, University of Technology Sydney, Sydney, NSW 2007, Australia; victoria.garciacardenas@uts. edu.au

Received 1 June 2020 Revised 30 January 2021 Accepted 16 February 2021

\section{Check for updates}

(C) Author(s) (or their employer(s)) 2021. Re-use permitted under CC BY-NC. No commercial re-use. See rights and permissions. Published by BMJ.

To cite: Torres-Robles A, Benrimoj SI, Gastelurrutia MA, et al. BMJ Qual Saf Epub ahead of print: [please include Day Month Year].

doi:10.1136/

bmjqs-2020-011671

\begin{abstract}
Background Non-adherence to medications continues to be a burden worldwide, with significant negative consequences. Community pharmacist interventions seem to be effective at improving medication adherence. However more evidence is needed regarding their impact on diseasespecific outcomes. The aim was to evaluate the impact of a community pharmacist-led adherence management intervention on adherence and clinical outcomes in patients with hypertension, asthma and chronic obstructive pulmonary disease (COPD).

Methods A 6-month cluster randomised controlled trial was conducted in Spanish community pharmacies. Patients suffering from hypertension, asthma and COPD were recruited. Patients in the intervention group received a medication adherence management intervention and the control group received usual care. The intervention was based on theoretical frameworks for changing patient behaviour. Medication adherence, disease-specific outcomes (Asthma Control Questionnaire (ACQ) scores, Clinical COPD Questionnaire (CCQ) scores and blood pressure levels) and disease control were evaluated. A multilevel regression model was used to analyse the data.

Results Ninety-eight pharmacies and 1186 patients were recruited, with 1038 patients completing the study. Patients receiving the intervention had an OR of $5.12(95 \% \mathrm{Cl} 3.20$ to $8.20, p<0.05$ ) of being adherent after the 6 months. At the end of the study, patients in the intervention group had lower diastolic blood pressure levels (mean difference (MD) $-2.88,95 \% \mathrm{Cl}-5.33$ to $-0.43, \mathrm{p}=0.02)$, lower CCQ scores (MD $-0.50,95 \% \mathrm{Cl}-0.82$ to $-0.18, \mathrm{p}<0.05)$ and lower ACQ scores (MD $-0.28,95 \% \mathrm{Cl}-0.56$ to $0.00, \mathrm{p}<0.05$ ) when compared with the control group.

Conclusions A community pharmacist-led medication adherence intervention was effective at improving medication adherence and clinical outcomes in patients suffering from hypertension, asthma and COPD. Future research should explore the implementation of these interventions in routine practice.
\end{abstract}

Trial registration number ACTRN12618000410257.

\section{INTRODUCTION}

Patients with chronic conditions rely on medications to treat and control their diseases. ${ }^{1}$ However, medication adherence (ie, the process by which patients take their medications as prescribed) is suboptimal. $^{2}$ Medication adherence is composed of initiation, implementation and discontinuation. ${ }^{3}{ }^{4}$ There is evidence that nearly $40 \%$ of patients with chronic conditions discontinue their medication after 1 year and 4\% never initiate their treatment. ${ }^{5}$ Similarly, implementation of the dosing regimen (ie, the extent to which a patient's actual dosing corresponds to the prescribed dosing regimen) has been shown to decline over time. ${ }^{6}$ This complex phenomenon is a preventable ${ }^{7}$ source of patient harm and poor health outcomes. It often leads to disease progression, lower quality of life, increased use of healthcare resources ${ }^{8}$ and increased morbidity and mortality. ${ }^{9}{ }^{10}$ It accounts for an estimated 125000 deaths per year in the USA, ${ }^{11}$ with annual costs per patient ranging from $\$ 949$ to $\$ 44190$ (US\$2015). ${ }^{12}$ This problem is especially relevant in chronic conditions such as hypertension, asthma and chronic obstructive pulmonary disease (COPD), three of the most prevalent non-communicable diseases in developed countries, whose prevalence continues to increase. ${ }^{13-15}$ Medication non-adherence rates in these conditions are high, reaching 50\% for antihypertensive medications 5 and between $20 \%$ and $80 \%$ for inhaled medications, ${ }^{16}{ }^{17}$ with $14 \%-20 \%$ patients failing to fill in their first prescription. ${ }^{18}$

Medication adherence interventions have the potential to improve clinical outcomes, patient's health-related quality of life ${ }^{19} 20$ and the efficiency of the 
healthcare system. ${ }^{21-23}$ Long-term multicomponent interventions involving behavioural change theories seem promising at improving adherence, ${ }^{24-26}$ probably because they target multiple determinants. ${ }^{27}$ However, previous research has reported a lack of convincing evidence regarding the efficacy of these interventions, mainly due to the wide heterogeneity in settings, participants, intervention types or adherence measures among others. Moreover, there seems to be a paucity of randomised controlled trials reporting an improvement in both adherence and clinical outcomes, ${ }^{28}$ despite ethical standards for adherence research dictating that attempts to improve adherence should be judged by their clinical benefits. ${ }^{28}$ In this regard, some evidence suggests that community pharmacist-led interventions may enhance both medication adherence ${ }^{29-32}$ and disease-specific clinical outcomes. ${ }^{33} 34$ However, these usually involve interventions that would be difficult to implement in usual care settings. The development of effective interventions that are implementable in routine practice settings still represents a challenge for quality improvement in patient care. ${ }^{35}$

Quality use of medicines is often included as a key objective in many national medicine policies, through the implementation of initiatives aiming at ensuring medicines are safely and effectively used. This usually includes mechanisms to monitor and manage medication adherence, which constitutes one of the overarching goals to improve healthcare quality and patient safety. ${ }^{36}$ In Spain, adherence management is one of the six professional services with national priority following a consensus among Spanish national professional pharmacy organisations. ${ }^{37}$ However, there is a lack of evidence on the effectiveness of a medication adherence intervention that can be further implemented into regular practice.

The objective of this study was to evaluate the effectiveness of a community pharmacist-led medication adherence management intervention for adult patients being treated with hypertension, asthma or COPD medications on medication adherence and clinical outcomes compared with usual care.

\section{METHODS}

This study has been reported following the Consolidated Standards of Reporting Trials guidelines for cluster trials. ${ }^{38}$

\section{Study design}

A cluster randomised controlled trial was undertaken in community pharmacies across six Spanish provinces (A Coruña, Albacete, Ciudad Real, Guadalajara, Soria and Tenerife), representing about $12 \%$ of the provinces and $7 \%$ of community pharmacies in Spain. ${ }^{39}$ Pharmacies were the unit of randomisation to minimise cross-contamination between study groups. A study protocol has been registered and approved by the Spanish Medication Agency (Agencia Española de
Medicamentos, 4DZRC79213). No incentives were provided to pharmacists or patients.

\section{Pharmacy recruitment}

An invitation letter to enrol in the study was sent to all the pharmacies in each province by the local pharmacy professional body. The inclusion criteria for pharmacies were: availability of a counselling area; availability of at least one pharmacist to provide the intervention; and the attendance of all pharmacists to an initial training session before the beginning of the study. Inclusion criteria were verified by the local pharmacy professional bodies and by members of the research team. Due to the nature of the intervention, cluster randomisation was used to minimise cross-contamination between study groups. Eligible pharmacies were the unit of randomisation. They were assigned by an independent researcher after they agreed to participate in the study to either an intervention group (IG) or control group (CG) using a computer-generated list of random numbers with ratio $1: 1$.

\section{Sample size calculation/sampling}

Sample size calculations were based on the difference of expected proportions between adherent patients in CG and IG at the end of the study. An absolute difference of $20 \%$ in the prevalence of adherent patients between both groups was considered of clinical relevance. ${ }^{4041} \mathrm{~A}$ two-tailed comparison test was applied, considering an $80 \%$ power, alpha $=0.05$ and assuming a $50 \%$ prevalence of non-adherent patients at baseline.

The sample size was increased to take into account the design effect (DEFF), calculated as: $\mathrm{DEFF}=1+[n c-1]^{*}$ ICC (intraclass correlation coefficient) (where $n c=7$, average size of the cluster estimated for 102 clusters; ICC $=0.05$ ), resulting in 1025 patients. This number was increased to account for a potential $20 \%$ loss to follow-up. Therefore, 1230 patients and 102 pharmacies were estimated to be required. Each pharmacy was required to recruit 12 patients: 4 suffering from hypertension, 4 from asthma and 4 from COPD.

\section{Patient recruitment}

Patients were recruited consecutively in the participant community pharmacies for 2 months. Filling a prescription (for new or/and existing prescribed medications) was the prompt for the pharmacist to initiate a conversation about the study with potential eligible patients. Patients' inclusion criteria were: 18 years or older; signature of the informed consent; ability to complete EuroQol-5D, ${ }^{42}$ Morisky-GreenLevine Medication Adherence Questionnaire (MGL MAQ), ${ }^{43}{ }^{44}$ Asthma Control Questionnaire (ACQ) ${ }^{45}$ or Clinical COPD Questionnaire (CCQ) ${ }^{46}$; and to have a prescribed medication for hypertension (ie, medications included in the Anatomical Therapeutic Chemical 
(ATC) classification system groups C02, C03, C07, C08 or C09), asthma or COPD (ATC group R03). Medication groups were defined as per the ATC classification system developed by the WHO. ${ }^{47}$ Hypertension, asthma and COPD were the target conditions due to their high prevalence and non-adherence rates. ${ }^{13-15}$ If patients suffered from more than one of those diseases, data were only collected for one condition. This was selected by the pharmacist on the basis of the number of patients to be recruited per disease. Patients were excluded if they: were collecting someone else's medication; were pregnant or lactating; could not attend the pharmacy on a regular basis; had previously participated in any adherence education programme or study; had communication limitations or any other impairment the recruiting pharmacist considered as precluding them from participating in the study. During recruitment, the pharmacist explained the general characteristics of the study (ie, study involving monthly visits to the pharmacy, in which patients had to respond to the pharmacist's questions about their medications and health), assessed the patient's willingness to participate and their eligibility criteria. Patients were blinded to the study design, group and hypotheses. Patients willing to participate received an information sheet and their signed informed consent was obtained. Subsequently, the pharmacist and the patient agreed on a date for the initial and subsequent visits.

Patients attended six face-to-face monthly visits, undertaken in the pharmacy's counselling area. Patients allocated to the IG received a protocolised medication adherence management intervention (figure 1) whereas patients in the CG received usual care (defined as the supply of medicines and medication-taking advice). In each visit, patients' data were collected and clinical variables recorded.

\section{Intervention group}

Patients in the IG received the medication adherence management intervention. It involved the provision of a complex intervention, ${ }^{48}$ based on behaviour change frameworks, aiming at identifying and addressing barriers for medication adherence through tailored strategies. The intervention included:

1. Pharmacist interview to assess adherence to medications for asthma, COPD or hypertension using the MGL MAQ. ${ }^{43} 44$

2. Classification of patients as non-adherent (nonintentional, intentional or combined) or adherent.

3. Identification of barriers for medication adherence. Barriers could be practical, defined as gaps in knowledge or skills; or perceptual, namely those associated with the patient's health beliefs and perceptions about the condition and their medications.

4. Intervention proposal using strategies tailored to the type of non-adherence and identified barriers (online supplemental appendix 1).

5. Application of the transtheoretical model of behavioural change ${ }^{49}$ by which the pharmacist elicited the patient's readiness to change while discussing the proposed strategies. $^{50}$

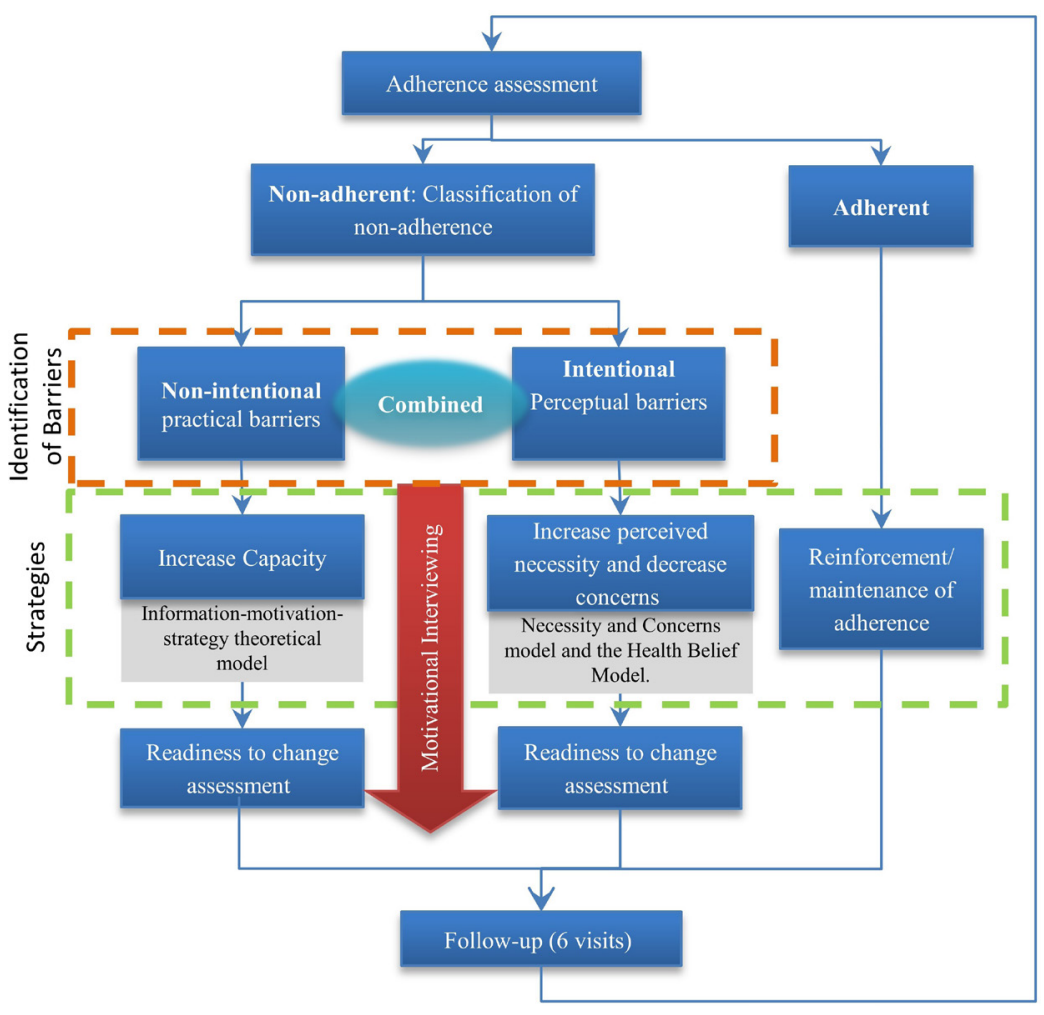

Figure 1 Adherence management intervention overview. 
6. Follow-up through monthly scheduled visits to review patient progress and provide feedback or new strategies to improve or maintain adherence.

7. Application of motivational interviewing principles and skills $^{2651}$ during the patient-pharmacist interaction.

\section{Pharmacist training}

Group and individualised training sessions were provided by the research team and by practice change facilitators (PCFs, external pharmacists who solved any problems or queries during the study through monthly visits and ensured compliance with the study protocol). Pharmacists in the IG received an initial training which covered the following topics: study protocol, management of the targeted conditions, frameworks for changing patient behaviour and educational skills to provide the intervention, over a 2-day session. Pharmacists in the CG were only trained in data collection and study procedures.

\section{Study outcomes}

Medication adherence (appropriate implementation of the dosing regimen) was the primary outcome, assessed by the MGL MAQ ${ }^{43} 44$ and reported as the percentage of adherent patients. Secondary outcomes included asthma control, COPD clinical health status and hypertension control. Asthma control was assessed using the ACQ-5. ${ }^{45}$ Results were reported as mean ACQ scores (scale 0-6, with lower scores indicating a better clinical control) and as the percentage of controlled patients $(\mathrm{ACQ} \leq 0.75)$. A difference of $\geq 0.5$ in mean scores was considered clinically significant. ${ }^{52}$ COPD clinical health status was assessed using the CCQ. ${ }^{46}$ Results were reported as mean CCQ scores (scale 0-6, with lower scores indicating a better clinical control) and as the percentage of patients with low clinical impact of the disease (scores <1.0). ${ }^{53}$ A difference $\geq 0.4$ between mean scores was considered clinically significant. ${ }^{54}$ In COPD, 'disease control' is not achieved, as normalisation of pulmonary function is not possible and patients may continue with exacerbations or limitations during daily life activities regardless of receiving treatment. ${ }^{55}$ Hypertension control was assessed through systolic blood pressure (SBP) and diastolic blood pressure (DBP) levels using a Visomat (Roche) (two measures, 3 min interval). Proportion of controlled patients (values $<140 \mathrm{~mm} \mathrm{Hg} / 90 \mathrm{~mm} \mathrm{Hg}^{56}$ and mean blood pressure (BP) levels were reported. All outcomes were measured in all study visits.

EuroQol data were collected in order to assess the cost-utility of the service. Results will be reported elsewhere.

\section{Blinding}

Patients were blinded to the intervention but given the nature of the intervention pharmacists were not. Only pharmacists in the IG were trained in the skills and knowledge required to deliver the intervention.
Data collection and quality

Study data were collected in an electronic data collection form, accessible by individual pharmacists through a personal username and password. Pharmacists directly recorded patient demographic data and observer-reported outcomes not involving judgement (ie, BP levels). Patient-reported outcomes (ie, medication adherence, ACQ scores and CCQ scores) were directly collected from patients. They completed the questionnaires in the electronic data collection form, requesting assistance from the pharmacist if needed.

PCFs monitored the quality of data entry and had their own access to the electronic data collection form to ensure data were being collected according to the protocol instructions. ${ }^{57}$ Patient data were protected and exported as dissociated for the statistical analysis. Only deidentified data from patients, pharmacists and pharmacies were available to the study researchers.

\section{Statistical analysis}

Data were analysed using the software package SPSS statistics (V.25.0, SPSS) and SAS/STAT V.9.4 (SAS Institute). Baseline patient-level information was summarised by treatment arm. A multilevel regression model with three levels (pharmacies, patients, visits) was conducted. It included a random intercept to account for the clustering by pharmacy and a correlation structure for the visits within patients, that accounted for changes in correlation of measurements over time (Toeplitz). A logistic regression model was used with this structure to estimate the ORs for the binary outcomes, and a similar linear mixed model was used for continuous outcomes. A likelihood ratio $p$ value (for the overall effect of the variable across visits) and a Wald $\mathrm{p}$ value for the test of treatment at each time point were estimated. Estimated rates with lower and upper levels were calculated. All patients with data collected from at least two time points during the study were included in the analysis. Estimated population margins were used to estimate the percentage of patients for binary outcomes and the average value for continuous outcomes by treatment and time period. Linear and generalised linear mixed models for the study outcomes were used, allowing for the assumption of 'missing-at-random' (ie, missing contingent on values included in the regression model) without requiring imputation for the missing outcomes (online supplemental appendix 2).

\section{RESULTS}

A total of 98 pharmacies and 138 pharmacists were recruited. Four pharmacies and four pharmacists dropped out from the study before starting patient recruitment and two pharmacies and three pharmacists dropped out during the study $(n=4$ IG, $n=2$ $\mathrm{CG})$. Patient recruitment was undertaken by pharmacists between October and November 2017, with 1186 patients enrolled (asthma: 385, COPD: 299, 


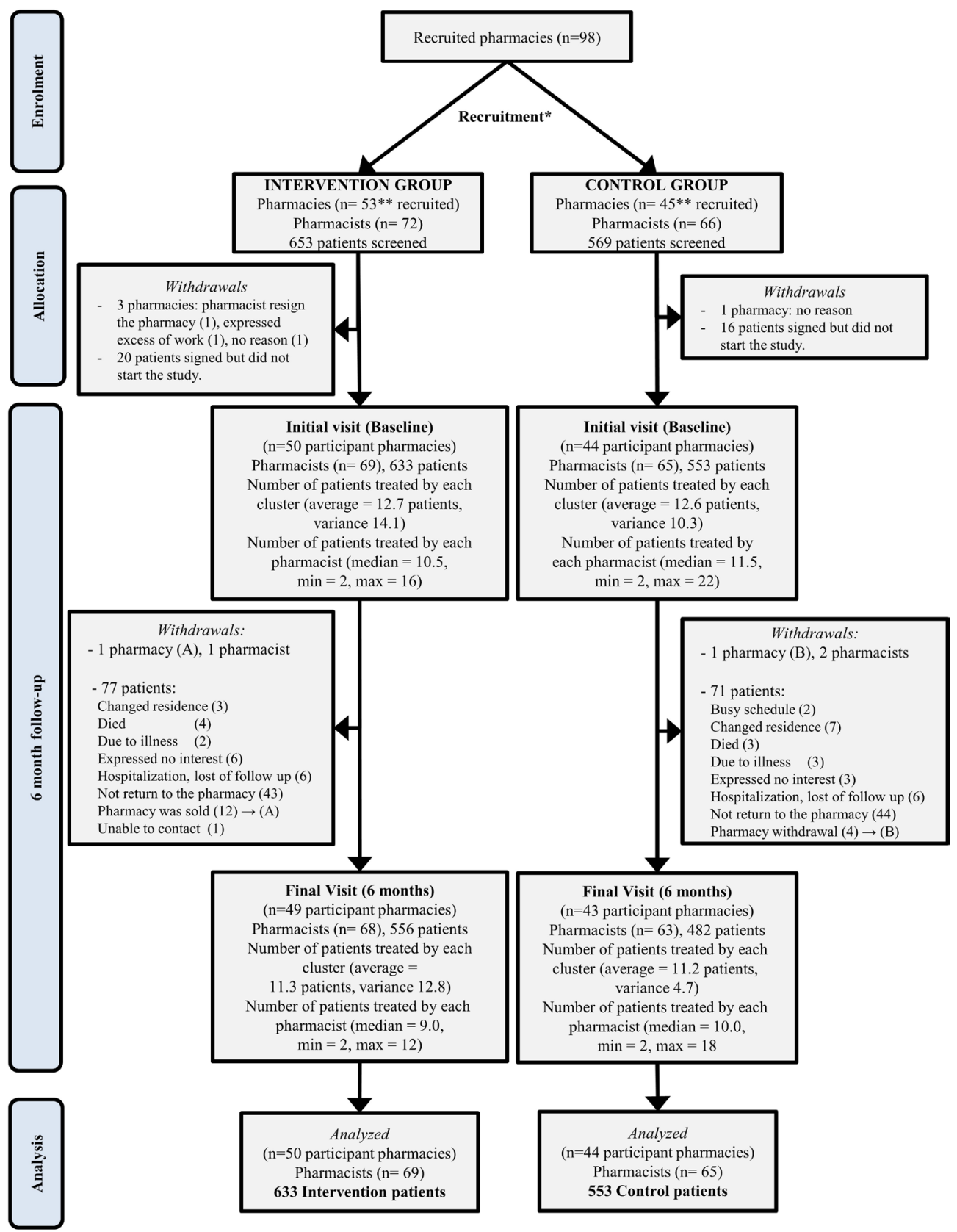

Figure 2 Flow chart of study participants. *Two hundred and eighteen patients were ineligible due to exclusion criteria: collecting someone else's medication (83), were pregnant or lactating (10), could not attend to the pharmacy on a regular basis (75), had previously participated in any adherence education programme or study (19), had communication limitations or any other impairment the recruiting pharmacist considered as precluding them from participating in the study (31). ${ }^{* *}$ The difference of eight recruited pharmacies is due to pharmacies that had previously participated in the 2-month pilot study and wanted to continue but could not be allocated to the control group. Therefore, they were allocated to the intervention group.

hypertension: 502) and 1038 patients (asthma: 333, COPD: 249, hypertension: 456) completing the study $(87.5 \%)$. Two hundred and eighteen patients were ineligible due to exclusion criteria (figure 2). Baseline patient characteristics are described in table 1.

\section{Medication adherence}

At baseline, the percentages of adherent patients were $39.1 \%$ (IG) and 44.3\% (CG). For individual follow-up periods, significant differences between study groups were observed from visit $3(\mathrm{p}<0.05)$ to visit 6 (OR
5.12, 95\% CI 3.20 to $8.20, \mathrm{p}<0.05$ ) (online supplemental appendix 3, figure 3). Overall, the absolute increase in the percentage of adherent patients during the study was higher in the IG $(51.8 \%)$ than in the CG $(22.2 \%) \quad(p<0.05)$. Disease-specific results are reported in the online supplemental appendix 4.

\section{Clinical control}

Hypertension

Mean baseline BP levels were similar in both study groups. Mean difference (MD) DBP between IG 


\begin{tabular}{|c|c|c|c|}
\hline Variables & $\begin{array}{l}\text { Control group } \\
(\mathrm{n}=553)\end{array}$ & $\begin{array}{l}\text { Intervention group } \\
(\mathrm{n}=633)\end{array}$ & $\begin{array}{l}\text { Total } \\
(\mathrm{n}=1186)\end{array}$ \\
\hline Age, mean $\pm S D$ & $64.0 \pm 15.4$ & $63.9 \pm 15.6$ & $64.0 \pm 15.5$ \\
\hline \multicolumn{4}{|l|}{ Gender, n (\%) } \\
\hline Male & $257(46.5)$ & $303(47.9)$ & $560(47.2)$ \\
\hline Female & $296(53.5)$ & $330(52.1)$ & $626(52.8)$ \\
\hline \multicolumn{4}{|l|}{ Education, n (\%) } \\
\hline No studies & $129(23.3)$ & $146(23.1)$ & $275(23.2)$ \\
\hline Primary & $201(36.3)$ & $258(40.8)$ & $459(38.7)$ \\
\hline High school & $125(22.6)$ & $151(23.9)$ & $276(23.3)$ \\
\hline Vocational degree & $13(2.4)$ & $9(1.4)$ & $22(1.9)$ \\
\hline University & $85(15.4)$ & $69(10.9)$ & $154(13.0)$ \\
\hline \multicolumn{4}{|l|}{ Working status, n (\%) } \\
\hline Paid employment & $137(24.8)$ & $138(21.8)$ & $275(23.2)$ \\
\hline $\begin{array}{l}\text { Paid employment but } \\
\text { on sick leave }\end{array}$ & $13(2.4)$ & $21(3.3)$ & $34(2.9)$ \\
\hline Unemployed & $51(9.2)$ & $62(9.8)$ & $113(9.5)$ \\
\hline Retired & $320(57.9)$ & $374(59.1)$ & $694(58.5)$ \\
\hline Student & $32(5.8)$ & $38(6.0)$ & $70(5.9)$ \\
\hline \multicolumn{4}{|l|}{ Clinical condition, $n(\%)$} \\
\hline Hypertension & $219(39.6)$ & $283(44.7)$ & $502(42.3)$ \\
\hline Asthma & $180(32.5)$ & $205(32.4)$ & $385(32.5)$ \\
\hline COPD & $154(27.8)$ & $145(22.9)$ & $299(25.2)$ \\
\hline $\begin{array}{l}\text { Medications prescribed } \\
\text { for the studied disease*, } \\
\text { mean (SD) }\end{array}$ & $1.84(0.98)$ & $1.91(1.08)$ & $1.88(1.04)$ \\
\hline $\begin{array}{l}\text { Total number of } \\
\text { prescribed medications, } \\
\text { mean (SD) }\end{array}$ & $5.72(3.48)$ & $5.69(3.32)$ & $5.71(3.39)$ \\
\hline $\begin{array}{l}\text { Total number of } \\
\text { diseasest, mean (SD) }\end{array}$ & $2.58(1.45)$ & $2.55(1.37)$ & $2.57(1.41)$ \\
\hline
\end{tabular}

and CG became statistically significant after visit 5 $(p<0.05)$. At the end of the study, there was a significant reduction in mean DBP in the IG when compared to the CG (MD $-2.88,95 \% \mathrm{CI}-5.33$ to -0.43 , $\mathrm{p}=0.02)$. Changes on SBP were not statistically significant (MD $-1.10,95 \% \mathrm{CI}-4.49$ to $2.29, \mathrm{p}=0.53$ ) (online supplemental appendix 3). Mean baseline percentages of controlled patients were similar in both groups $(\mathrm{IG}=55.5 \%, \mathrm{CG}=52.9 \%)$. These percentages increased in both groups, with no difference between groups at the end of the study (OR 1.22, 95\% CI 0.78 to $1.91, \mathrm{p}=0.38$ ) (online supplemental appendix 3, figure 3 ).

Asthma

Mean baseline ACQ scores were similar in the IG and CG $(p=0.98)$. A gradual decrease was observed in both groups until reaching significant differences in visit 5 , favouring the IG $(\mathrm{p}<0.05)$. Mean scores decreased 0.53 (IG) and 0.26 points (CG) between baseline and visit 6 . Only the diminution in the IG was clinically significant. At visit 6 , mean ACQ scores were significantly lower in the IG (MD $-0.28,95 \%$ CI -0.56 to $0.00, \mathrm{p}<0.05)$, indicating a better asthma control (online supplemental appendix 3). Percentages of controlled patients at baseline were similar (IG: 37.3\%; CG: 43.8\%). Statistically significant differences were evident after visit 5 . Percentages of controlled patients at the end of the study were significantly higher in the IG (72.0\%) when compared with the CG (57.8\%) (OR $1.88,95 \%$ CI 1.05 to $3.36, \mathrm{p}=0.03$ ) (online supplemental appendix 3) (figure 3).

Chronic obstructive pulmonary disease

Mean baseline CCQ scores were 1.79 (IG) and 2.10 $(\mathrm{CG})(\mathrm{p}<0.05)$. Mean scores decreased in both groups across study visits, with significant differences being evident after visit $3(\mathrm{p}<0.05)(\mathrm{MD}$ at visit $6-0.50$, $95 \% \mathrm{CI}-0.82$ to $0.18, \mathrm{p}<0.05$ ) (online supplemental

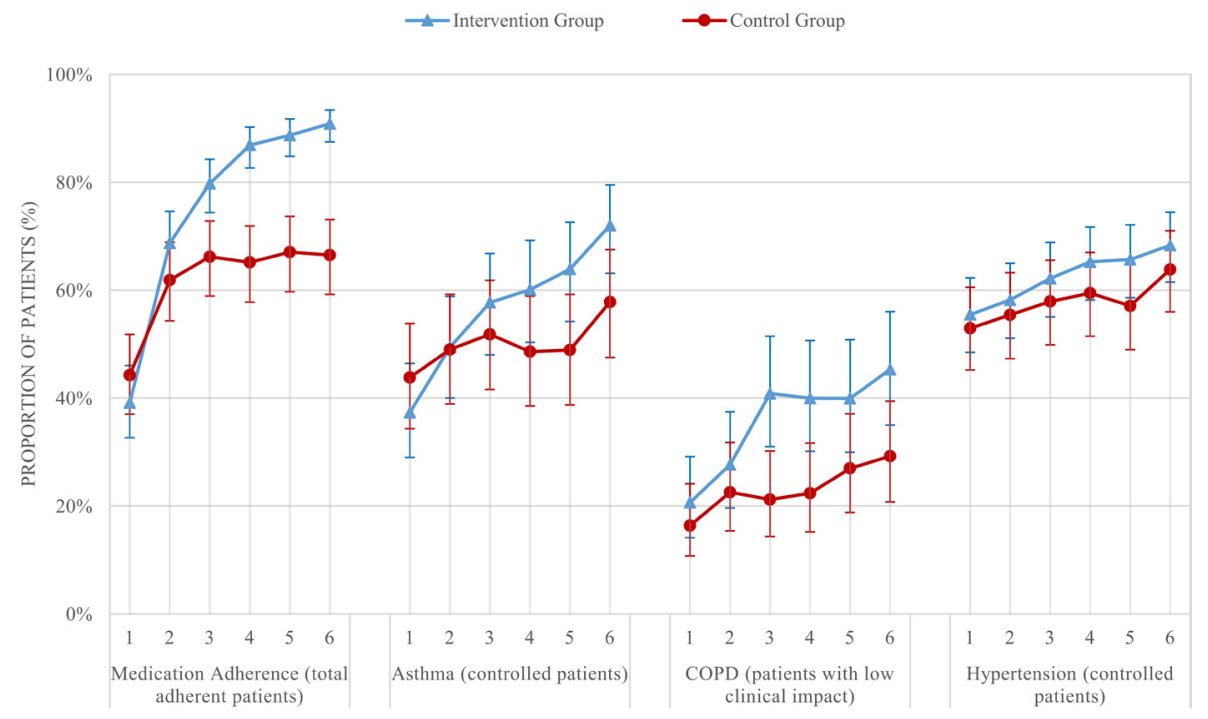

VISIT/OUTCOME

Figure 3 Categorical outcomes per study group and study visit. COPD, chronic obstructive pulmonary disease. 
appendix 3). A reduction of 0.39 (CG) and 0.58 (IG) points in the mean scores was observed at the end of the 6-month period, with the latter being clinically significant. At baseline, percentages of patients with low clinical impact of the disease (ie, low level of symptoms) were $20.6 \%$ (IG) and $16.3 \%$ (CG) at baseline (figure 3). These percentages increased across study visits in both groups, with significant differences favouring the IG after visit $3(p<0.05)$. At the end of the study, the percentage of patients with low clinical impact of COPD was significantly larger in the IG (OR $2.01,95 \%$ CI 1.07 to $3.75, \mathrm{p}<0.05$ ) (online supplemental appendix 3).

\section{DISCUSSION}

A community pharmacist-led medication adherence management intervention resulted in improvements in medication adherence and clinical outcomes. Significant increases in the percentage of patients adhering to their dosing regimen and improvements in COPD outcomes were evident after 3 months of follow-up. In the case of asthma outcomes and DBP significant improvements were observed after 5 months.

The observed baseline percentage of adherent patients, close to $50 \%$, aligned with the figures previously reported by the WHO. ${ }^{58}$ Interestingly, there was a gradual increase in these percentages, reaching statistically significant differences between study groups at visit 3 . The percentage of adherent patients in the CG was found to remain constant during the following visits, always below $70 \%$. In the IG, this percentage progressively increased during all study visits. At the end of the study, $90 \%$ of patients were adherent to their medications, doubling the baseline percentage in the IG and being nearly $25 \%$ more than in the CG. Previous studies assessing the effectiveness of pharmacists' interventions using a similar follow-up period have found between $10 \%$ and $40 \%$ increase in the percentage of adherent patients. ${ }^{175960}$ One study targeted patients using new prescribed medications and found a $10 \%$ increase in the percentage of adherent patients after 10 weeks of follow-up, but decreased after 26 weeks. ${ }^{61}$ This study consisted of one initial consultation and one follow-up consultation 5 weeks later. ${ }^{61}$ Our study resulted in a larger increase $(51.8 \%)$, probably due to the core components of the brief complex intervention, continuous follow-up and fidelity monitoring of the intervention provision.

These results highlight the importance of continuous follow-up in medication adherence management. Evidence supports that interventions provided on a regular basis are more likely to increase adherence than a single intervention, signalling adherence management interventions are to be maintained as long as the treatment is needed. ${ }^{28}$ Similarly, interventions delivered across multiple visits are more effective than those delivered during a single visit. ${ }^{62}$ Our results align with these findings, suggesting adherence interventions should be delivered for at least 3 months to be effective.

There is evidence in the literature indicating that pharmacist-led interventions improve medication adherence in patients with asthma, COPD and hypertension. $^{32}{ }^{63}$ However, limited information exists regarding the description of effective interventions, making it difficult to replicate these in real practice. There has been a call to generate more evidence on the impact of these interventions on disease-specific clinical outcomes. ${ }^{28}$ Due to the negative impact medication non-adherence has on the patient's outcomes, adherence management has been considered a key element in the development of quality improvement initiatives. ${ }^{35}$ Moreover, monitoring patient outcomes and medication management skills are essential when delivering interventions aiming at improving quality and safe medicines use. ${ }^{64}$

Core components of the intervention were based on evidence-based behaviour change frameworks to tailor specific patient needs and elicit medication adherence improvement. Including cognitive-based behaviour techniques resulted in adherence improvements. ${ }^{65} \mathrm{~A}$ recent meta-analysis stated the importance of cognitive and behavioural components to effectively change adherence behaviour. ${ }^{25}$ However, there is no evidence supporting that a single theory should be used. ${ }^{66}$ We considered a range of strategies tailored to each patient's individual needs, including educational components or reminders, as they have shown to be effective in chronic conditions, ${ }^{67} 68$ such as hypertension. ${ }^{69}$ Our findings align with previous studies, which have shown increases in medication adherence and decreases in BP levels. ${ }^{41607071}$ Although our intervention resulted in a larger increase in the proportion of controlled patients in the IG (12.8\%) when compared with the CG, differences between study groups were not statistically significant at the end of the study. This could be due to the low mean baseline BP levels of included patients and to uncontrolled hypertension not being a patient inclusion criterion. Additionally, BP changes may also take longer to manifest, as differences in DBP levels started to be significant after 5 months of follow-up. Consistent with other studies that reported reductions of 3-11 $\mathrm{mm} \mathrm{Hg}$ (DBP) and 7-30 mm Hg (SBP), ${ }^{41} 60$ 71-74 our study reported a reduction of $3.3 \mathrm{~mm} \mathrm{Hg}$ in $\mathrm{SBP}$ and $2.5 \mathrm{~mm} \mathrm{Hg}$ in DBP levels. Non-adherence has been associated with a high DBP, thereby an improvement of medication adherence can positively impact in DBP and hypertension control. ${ }^{75-77}$

Pharmacists' interventions in patients with respiratory conditions such as counselling and education have also found to be effective at improving clinical outcomes. ${ }^{33}$ Our proposed intervention resulted in a larger increase in the percentage of controlled patients (34.7\%), when compared with previous studies that reported $13 \%-30 \% .{ }^{1778}$ The reduction of 0.53 points 
in mean ACQ scores was clinically significant ${ }^{52}$ and similar to previous studies. ${ }^{17} 78$ Similarly, an improvement on the average score and percentage of patients with low clinical impact of COPD was observed. Unlike previous studies, ${ }^{40} 79$ our intervention resulted in clinically $^{54}$ and statistically significant differences in mean CCQ scores from visit 3 until the end of the study, indicating the intervention was effective at improving clinical outcomes in patients with COPD.

To the best of our knowledge, this is the first study proposing a medication adherence management intervention in community pharmacies in Spain using complex interventions based on theories and frameworks of behaviour change and reporting clinical outcomes; targeting one of the priority Spanish pharmacy services ${ }^{37}$ and one of the key goals of healthcare. ${ }^{35}$ The novelty of this study is the proposal of a structured patient-tailored pharmacist intervention based on evidence-based frameworks ${ }^{25}$ and assessment of clinical variables in a community pharmacy setting. Although there is some evidence supporting the use of these frameworks in patients suffering from hypertension, it is limited for patients with asthma or COPD.

\section{Practice implications}

Findings of this study provide evidence on the effectiveness of a patient-targeted intervention and support the future implementation of a medication adherence management service in regular practice.

\section{Limitations}

Objective adherence measures such as dispensing data could not be used. There was a lack of interoperability between pharmacies hindering the access to dispensing records. Therefore, only implementation adherence through a self-reported method was assessed, which may have been affected by desirability bias. Nonetheless, in the absence of a gold standard, ${ }^{80}$ patient selfreported questionnaires have a close correlation with electronic monitoring devices. ${ }^{81}$ Due to the nature of the intervention, pharmacist blinding was impossible. This is common in studies evaluating educational interventions. The intervention's design required the collection of data as part of the patient's evaluation and the provision of the intervention. Therefore, it was impossible to include a blinded data collector. Blinding personnel and intervention providers is often not achievable for studies assessing educational interventions. Potential risk of bias derived from lack of blinding for pharmacists was minimised, as the main study outcomes were either participant-reported outcomes (ie, patients who were blinded to the study group) or observer-reported outcomes not involving judgement.

Positive effects were also observed in the CG for medication adherence, asthma and COPD control during the first 2 months of study. Patients often modify their behaviour when feeling observed (ie, Hawthorne effect). Moreover, data collection could have made patients more conscious of their behaviours and have impacted their health. Finally, control pharmacists may have provided more information than they would provide during usual care, even if they were instructed not to change their regular practice.

\section{CONCLUSION}

A structured patient-targeted intervention based on behavioural change frameworks and the assessment of clinical variables proved to be effective at improving medication adherence and disease-specific clinical outcomes in patients with hypertension, asthma and COPD. Overall, intergroup differences were significant after 3 months of follow-up, highlighting the importance of continuous monitoring in the management of medication adherence. This study proposes an approach to address patient safety and quality of care through adherence management. Integrating prescribing and pharmacy data would increase the potential of the intervention by measuring all dimensions of medication adherence. Future research should explore the implementation of these interventions in routine practice.

Contributors VGC, SIB, MÁG and FMM were involved in the conception of the work. ATR, VGC, TP, RVD, BPE and MIVM were involved in the codesign of the work and oversight of data collection. KR led the statistical design and assisted with data analysis and interpretation. ATR and VGC led the drafting of the manuscript. All authors have read and approved the final manuscript.

Funding This project was funded and supported by Laboratorios Cinfa.

Competing interests None declared.

Patient consent for publication Not required.

Ethics approval This trial follows the Ethical Principles for Medical Research Involving Human Subjects and Good Clinical Practice and International Council for Harmonisation. It was approved by the Ethics Committee of Research of Granada (CEI-Granada) (registration number: 0021-N-17).

Provenance and peer review Not commissioned; externally peer reviewed.

Data availability statement Data are available upon reasonable request to the corresponding author.

Supplemental material This content has been supplied by the author(s). It has not been vetted by BMJ Publishing Group Limited (BMJ) and may not have been peer-reviewed. Any opinions or recommendations discussed are solely those of the author(s) and are not endorsed by BMJ. BMJ disclaims all liability and responsibility arising from any reliance placed on the content. Where the content includes any translated material, BMJ does not warrant the accuracy and reliability of the translations (including but not limited to local regulations, clinical guidelines, terminology, drug names and drug dosages), and is not responsible for any error and/or omissions arising from translation and adaptation or otherwise.

Open access This is an open access article distributed in accordance with the Creative Commons Attribution Non Commercial (CC BY-NC 4.0) license, which permits others to distribute, remix, adapt, build upon this work noncommercially, and license their derivative works on different terms, provided the original work is properly cited, appropriate credit is given, any changes made indicated, and the use is non- 
commercial. See: http://creativecommons.org/licenses/by-nc/4. $0 /$.

\section{ORCID iD}

Victoria Garcia-Cardenas http://orcid.org/0000-0003-37704557

\section{REFERENCES}

1 Liska J, Beal A. One patient is not one condition: delivering patient-centered care to those with multiple chronic conditions. Ther Innov Regul Sci 2017;51:468-70.

2 Vrijens B, De Geest S, Hughes DA, et al. A new taxonomy for describing and defining adherence to medications. Br J Clin Pharmacol 2012;73:691-705.

3 De Geest S, Ruppar T, Berben L, et al. Medication nonadherence as a critical factor in the management of presumed resistant hypertension: a narrative review. EuroIntervention 2014;9:1102-9.

4 De Geest S, Zullig LL, Dunbar-Jacob J, et al. ESPACOMP medication adherence reporting guideline (emerge). Ann Intern Med 2018;169:30-5.

5 Blaschke TF, Osterberg L, Vrijens B, et al. Adherence to medications: insights arising from studies on the unreliable link between prescribed and actual drug dosing histories. Annu Rev Pharmacol Toxicol 2012;52:275-301.

6 Torres-Robles A, Wiecek E, Cutler R, et al. Using dispensing data to evaluate adherence implementation rates in community pharmacy. Front Pharmacol 2019;10:130.

7 Zullig LL, Blalock DV, Dougherty S, et al. The new landscape of medication adherence improvement: where population health science meets precision medicine. Patient Prefer Adherence 2018;12:1225-30.

8 Jimmy B, Jose J. Patient medication adherence: measures in daily practice. Oman Med J 2011;26:155-9.

9 Ho PM, Rumsfeld JS, Masoudi FA, et al. Effect of medication nonadherence on hospitalization and mortality among patients with diabetes mellitus. Arch Intern Med 2006;166:1836-41.

10 GBD 2016 Disease and Injury Incidence and Prevalence Collaborators. Global, regional, and national incidence, prevalence, and years lived with disability for 328 diseases and injuries for 195 countries, 1990-2016: a systematic analysis for the global burden of disease study 2016. Lancet 2017;390:1211-59.

11 McCarthy R. The price you pay for the drug not taken. Bus Health 1998;16:27-8.

12 Cutler RL, Fernandez-Llimos F, Frommer M, et al. Economic impact of medication non-adherence by disease groups: a systematic review. BMJ Open 2018;8:e016982.

13 Mills KT, Bundy JD, Kelly TN, et al. Global disparities of hypertension prevalence and control: a systematic analysis of population-based studies from 90 countries. Circulation 2016;134:441-50.

14 Masoli M, Fabian D, Holt S, et al. The global burden of asthma: Executive summary of the GINA dissemination Committee report. Allergy 2004;59:469-78.

15 GBD 2015 Chronic Respiratory Disease Collaborators. Global, regional, and national deaths, prevalence, disability-adjusted life years, and years lived with disability for chronic obstructive pulmonary disease and asthma, 1990-2015: a systematic analysis for the global burden of disease study 2015. Lancet Respir Med 2017;5:691-706.

16 Mueller S, Wilke T, Bechtel B, et al. Non-persistence and non-adherence to long-acting COPD medication therapy: a retrospective cohort study based on a large German claims dataset. Respir Med 2017;122:1-11.

17 García-Cárdenas V, Sabater-Hernández D, Kenny P, et al. Effect of a pharmacist intervention on asthma control. A cluster randomised trial. Respir Med 2013;107:1346-55.

18 Wu AC, Butler MG, Li L, et al. Primary adherence to controller medications for asthma is poor. Ann Am Thorac Soc 2015;12:161-6.

19 Andersson F, Borg S, Jansson SA, et al. The costs of exacerbations in chronic obstructive pulmonary disease (COPD). Respir Med 2002;96:700-8.

20 Pittman DG, Tao Z, Chen W, et al. Antihypertensive medication adherence and subsequent healthcare utilization and costs. Am J Manag Care 2010;16:568-76.

21 Toy EL, Beaulieu NU, McHale JM, et al. Treatment of COPD: relationships between daily dosing frequency, adherence, resource use, and costs. Respir Med 2011;105:435-41.

22 Mäkelä MJ, Backer V, Hedegaard M, et al. Adherence to inhaled therapies, health outcomes and costs in patients with asthma and COPD. Respir Med 2013;107:1481-90.

23 Sokol MC, McGuigan KA, Verbrugge RR, et al. Impact of medication adherence on hospitalization risk and healthcare cost. Med Care 2005;43:521-30.

24 Wiecek E, Tonin FS, Torres-Robles A, et al. Temporal effectiveness of interventions to improve medication adherence: a network meta-analysis. PLoS One 2019;14:e0213432.

25 Conn VS, Enriquez M, Ruppar TM, et al. Meta-Analyses of theory use in medication adherence intervention research. Am J Health Behav 2016;40:155-71.

26 Zomahoun HTV, Guénette L, Grégoire J-P, et al. Effectiveness of motivational interviewing interventions on medication adherence in adults with chronic diseases: a systematic review and meta-analysis. Int J Epidemiol 2017;46:589-602.

27 Kardas P, Lewek P, Matyjaszczyk M. Determinants of patient adherence: a review of systematic reviews. Front Pharmacol 2013;4:91.

28 Nieuwlaat R, Wilczynski N, Navarro T, et al. Interventions for enhancing medication adherence. Cochrane Database Syst Rev 2014;11:CD000011.

29 Wu JYF, Leung WYS, Chang S, et al. Effectiveness of telephone counselling by a pharmacist in reducing mortality in patients receiving polypharmacy: randomised controlled trial. $B M J$ 2006;333:522.

30 Morgado MP, Morgado SR, Mendes LC, et al. Pharmacist interventions to enhance blood pressure control and adherence to antihypertensive therapy: review and meta-analysis. Am J Health Syst Pharm 2011;68:241-53.

31 Pringle JL, Boyer A, Conklin MH, et al. The Pennsylvania project: pharmacist intervention improved medication adherence and reduced health care costs. Health Aff 2014;33:1444-52.

32 Conn VS, Ruppar TM. Medication adherence outcomes of 771 intervention trials: systematic review and meta-analysis. Prev Med 2017;99:269-76.

33 Garcia-Cardenas V, Armour C, Benrimoj SI, et al. Pharmacists' interventions on clinical asthma outcomes: a systematic review. Eur Respir J 2016;47:1134-43.

34 Omboni S, Caserini M. Effectiveness of pharmacist's intervention in the management of cardiovascular diseases. Open Heart 2018;5:e00687. 
35 Franklin BD, Abel G, Shojania KG. Medication non-adherence: an overlooked target for quality improvement interventions. BMJ Qual Saf 2020;29:271-3.

36 Nanji KC, Ferris TG, Torchiana DF, et al. Overarching goals: a strategy for improving healthcare quality and safety? BMJ Qual Saf 2013;22:187-93.

37 Sexto C. Foro AF-FC Servicios Profesionales Farmaceuticos Asistenciales: definicion Y clasificacion. Panorama Actual del Medicamento 2016;40:709-11.

38 Campbell MK, Piaggio G, Elbourne DR, et al. Consort 2010 statement: extension to cluster randomised trials. BMJ 2012;345:e5661.

39 Instituto Nacional de Estadistica [Cifras oficiales, resumen por provincias]. Available: https://www.ine.es/jaxiT3/Tabla.htm?t= 2852 [Accessed 08 Sep 2020].

40 Jarab AS, Alqudah SG, Khdour M, et al. Impact of pharmaceutical care on health outcomes in patients with COPD. Int J Clin Pharm 2012;34:53-62.

41 Morgado M, Rolo S, Castelo-Branco M. Pharmacist intervention program to enhance hypertension control: a randomised controlled trial. Int J Clin Pharm 2011;33:132-40.

42 Badia X, Roset M, Montserrat S, et al. [The Spanish version of EuroQol: a description and its applications. European Quality of Life scale]. Med Clin 1999;112 Suppl 1:79-85.

43 Morisky DE, Green LW, Levine DM. Concurrent and predictive validity of a self-reported measure of medication adherence. Med Care 1986;24:67-74.

44 Val Jiménez A, Amorós Ballestero G, Martínez Visa P, et al. [Descriptive study of patient compliance in pharmacologic antihypertensive treatment and validation of the Morisky and Green test]. Aten Primaria 1992;10:767-70.

45 Vega JM, Badia X, Badiola C, et al. Validation of the Spanish version of the asthma control test (act). J Asthma 2007;44:867-72.

46 Ställberg B, Nokela M, Ehrs P-O, et al. Validation of the clinical COPD questionnaire (CCQ) in primary care. Health Qual Life Outcomes 2009;7:26.

47 WHO. ATC/DDD index 2019, 2019. Available: https://www. whocc.no/atc_ddd_index/ [Accessed Oct 2019].

48 Craig P, Dieppe P, Macintyre S, et al. Developing and evaluating complex interventions: the new medical Research Council guidance. BMJ 2008;337:a1655.

49 Johnson SS, Driskell M-M, Johnson JL, et al. Transtheoretical model intervention for adherence to lipid-lowering drugs. Dis Manag 2006;9:102-14.

50 DiClemente CC, Prochaska JO, Fairhurst SK, et al. The process of smoking cessation: an analysis of precontemplation, contemplation, and preparation stages of change. J Consult Clin Psychol 1991;59:295-304.

51 Hugtenburg JG, Timmers L, Elders PJ, et al. Definitions, variants, and causes of nonadherence with medication: a challenge for tailored interventions. Patient Prefer Adherence 2013;7:675-82.

52 Juniper EF, Svensson K, Mörk A-C, et al. Measurement properties and interpretation of three shortened versions of the asthma control questionnaire. Respir Med 2005;99:553-8.

53 Tsiligianni IG, Alma HJ, de Jong C, et al. Investigating sensitivity, specificity, and area under the curve of the clinical COPD questionnaire, COPD assessment test, and modified medical Research Council scale according to gold using St George's respiratory questionnaire cutoff 25 (and 20) as reference. Int J Chron Obstruct Pulmon Dis 2016;11:1045-52.
54 Kocks JWH, Tuinenga MG, Uil SM, et al. Health status measurement in COPD: the minimal clinically important difference of the clinical COPD questionnaire. Respir Res 2006;7:62.

55 Soler-Cataluña JJ, Alcázar-Navarrete B, Miravitlles M. The concept of control of COPD in clinical practice. Int J Chron Obstruct Pulmon Dis 2014;9:1397-405.

56 James PA, Oparil S, Carter BL, et al. 2014 evidence-based guideline for the management of high blood pressure in adults: report from the panel members appointed to the eighth joint National Committee (JNC 8). JAMA 2014;311:507-20.

57 Berta W, Cranley L, Dearing JW, et al. Why (we think) facilitation works: insights from organizational learning theory. Implement Sci 2015;10:141.

58 Sabate E. Adherence to long term therapies, evidence for action. World Health Organization, 2003.

59 Armour C, Bosnic-Anticevich S, Brillant M, et al. Pharmacy asthma care program (PACP) improves outcomes for patients in the community. Thorax 2007;62:496-592.

60 Stewart K, George J, Mc Namara KP, et al. A multifaceted pharmacist intervention to improve antihypertensive adherence: a cluster-randomized, controlled trial (happy trial). J Clin Pharm Ther 2014;39:527-34.

61 Elliott RA, Boyd MJ, Tanajewski L, et al. 'New medicine service': supporting adherence in people starting a new medication for a long-term condition: 26-week follow-up of a pragmatic randomised controlled trial. BMJ Qual Saf 2020;29:286-95.

62 Conn VS, Ruppar TM, Chase J-AD, et al. Interventions to improve medication adherence in hypertensive patients: systematic review and meta-analysis. Curr Hypertens Rep 2015;17:94.

63 Milosavljevic A, Aspden T, Harrison J. Community pharmacistled interventions and their impact on patients' medication adherence and other health outcomes: a systematic review. Int J Pharm Pract 2018;26:387-97.

64 Commonwealth. Department of health and ageing. The National strategy for quality use of medicines, 2002. Available: https://www1.health.gov.au/internet/main/ publishing.nsf/Content/Publications-16 [Accessed 01 Oct 2020].

65 Easthall C, Song F, Bhattacharya D. A meta-analysis of cognitive-based behaviour change techniques as interventions to improve medication adherence. BMJ Open 2013;3:e02749.

66 Blalock SJ. The theoretical basis for practice-relevant medication use research: patient-centered/behavioral theories. Res Social Adm Pharm 2011;7:317-29.

67 Tao D, Xie L, Wang T, et al. A meta-analysis of the use of electronic reminders for patient adherence to medication in chronic disease care. J Telemed Telecare 2015;21:3-13.

68 Demonceau J, Ruppar T, Kristanto P, et al. Identification and assessment of adherence-enhancing interventions in studies assessing medication adherence through electronically compiled drug dosing histories: a systematic literature review and meta-analysis. Drugs 2013;73:545-62.

69 Torres-Robles A, Wiecek E, Tonin FS, et al. Comparison of interventions to improve long-term medication adherence across different clinical conditions: a systematic review with network meta-analysis. Front Pharmacol 2018;9:1454.

70 Blenkinsopp A, Phelan M, Bourne J, et al. Extended adherence support by community pharmacists for patients with hypertension: a randomised controlled trial. Int J Pharm Pract 2000;8:165-75. 
71 Lee JK, Grace KA, Taylor AJ. Effect of a pharmacy care program on medication adherence and persistence, blood pressure, and low-density lipoprotein cholesterol: a randomized controlled trial. JAMA 2006;296:2563-71.

72 Carter BL, Ardery G, Dawson JD, et al. Physician and pharmacist collaboration to improve blood pressure control. Arch Intern Med 2009;169:1996-2002.

73 Machado M, Bajcar J, Guzzo GC, et al. Sensitivity of patient outcomes to pharmacist interventions. Part II: systematic review and meta-analysis in hypertension management. Ann Pharmacother 2007;41:1770-81.

74 Aguiar PM, Balisa-Rocha BJ, Brito GC, et al. Pharmaceutical care program for elderly patients with uncontrolled hypertension. J Am Pharm Assoc 2012;52:515-8.

75 Avataneo V, De Nicolò A, Rabbia F, et al. Therapeutic drug monitoring-guided definition of adherence profiles in resistant hypertension and identification of predictors of poor adherence. Br J Clin Pharmacol 2018;84:2535-43.

76 Wu J-R, Cummings DM, Li Q, et al. The effect of a practice-based multicomponent intervention that includes health coaching on medication adherence and blood pressure control in rural primary care. J Clin Hypertens 2018;20:757-64.

77 Hennein R, Hwang S-J, Au R, et al. Barriers to medication adherence and links to cardiovascular disease risk factor control: the Framingham heart study. Intern Med J 2018;48:414-21.

78 Armour CL, Reddel HK, LeMay KS, et al. Feasibility and effectiveness of an evidence-based asthma service in Australian community pharmacies: a pragmatic cluster randomized trial. $J$ Asthma 2013;50:302-9.

79 McGeoch GRB, Willsman KJ, Dowson CA, et al. SelfManagement plans in the primary care of patients with chronic obstructive pulmonary disease. Respirology 2006;11:611-8.

80 Whalley Buono E, Vrijens B, Bosworth HB, et al. Coming full circle in the measurement of medication adherence: opportunities and implications for health care. Patient Prefer Adherence 2017;11:1009-17.

81 Shi L, Liu J, Koleva Y, et al. Concordance of adherence measurement using self-reported adherence questionnaires and medication monitoring devices. Pharmacoeconomics 2010;28:1097-107. 